\title{
Study of the plastic-hinge analysis of 3D steel frames applying nonlinear static analysis
}

\author{
Haitham Kannas $^{1^{*}}$, Abdallah M.S. Wafi ${ }^{1}$ \\ ${ }^{\text {I} C i v i l ~ E n g i n e e r i n g ~ D e p a r t m e n t, ~ N e a r ~ E a s t ~ U n i v e r s i t y, ~ N i c o s i a, ~ V i a ~ M e r s i n ~ 10, ~ T u r k e y ~}$
}

ARTICLE INFO

ARTICLE HISTORY:

Received: 24 February 2020

Revised: 06 May 2020

Accepted: 06 May 2020

Published: 28 June 2020

\section{KEYWORDS:}

Pushover analysis, plastic hinge, stiffness, lateral load

\section{A B S T R A C T}

This paper provides a distinct study on the performance of different residential buildings with different height and length spans under the influence of applied loads according to the Turkish standard TS498. The research paper presents the nonlinear performance of the buildings and provides a clear picture of the plastic and its stages throughout the construction. The study explains the effect of the various stages of plastic and how it affects the rigidity of the building. The results portray the building's stiffness values and how they change. The results show that stiffness increases with length-increase and decreases by decreasing the height of buildings. All stiffness values were calculated according to the first plastic hinge formation. Software used is ETABS 2018 and all calculations and parameters used according to FEMA356-2000, ASCE 7-16, ACI-318, EURO code 8, and Turkish standard.

\section{INTRODUCTION}

All global codes are now looking to work with performance-based design, a small part of it being Pushover Analysis. This study focuses on knowing, what is performance-based design and Pushover Analysis? Also, how the global codes will be used and how traditional methods such as equivalent static and response spectrum are not used commonly anymore.

Typically, if engineers wanted to enter the earthquake load on the building, they would consider that the load is $10 \%$ of the building's weight value (NCSC2015). With updated knowledge regarding the science of ground motion, engineers started taking into perspective the dynamic characteristics. They discovered that different facilities respond in different ways to the same earthquake according to the time-period and the ductility of the building. Also, how the ductility is expressed by codes through a parameter which is $R$. $R$ is an estimated value, which causes difficulty since it is not accurate. If a building is designed based on the unknown value of $\mathrm{R}$ and an earthquake were to occur, the building could very easily collapse. Therefore, the idea of designing a building to perform on its own came to question. That can be done by studying the performance of the building during an earthquake. Through that, the idea of performance-based design formed (Macedo et al., 2019; Leelataviwat et al., 2015).

Force-based design is a traditional method that we depend on in modern day designing, providing strength in order for the building to resist any external load that might affect it, and stiffness to strengthen the serviceability requirements of the building. Force-based design is also a method that counters the static method and relies on the building for an estimated force capacity and design force capacity and the force it provides must not exceed its design force capacity (Habibullah \& Pyle, 1998).

This method is reliable in case of small earthquakes and is useless in the case of large earthquakes. Therefore, we turned to deformation and the nonlinear relationship between strength and deformation. Whereas instead of saying there is a force capacity that should not be overlooked, we say that there is deformation that should not be missed.

Deformation based design, the strength that the building can withstand, will not be discussed. Rather the amount of deformation that can happen to the building. It simply means that instead of asking what the force capacity is, the question should be the deformation capacity, which is the 
method of deformation-based design. Also, in which we have been dealing with the nonlinearity that is happening instead of relying on the linear behaviour in the force method-based design. Therefore, it should be depending on the amount of deformation capacity in the building (Sullivan et al. 2018).

So, there are two important factors to consider:

- The deformation capacity is the amount of deformation allowed for the building. Which depends on the ductility and the amount of cracking in the building.

- The deformation demand, which is caused by the earthquake.

If the length of the deformation demand caused by the earthquake is less than the deformation capacity, our building is safe.

Even this method is flawed because it neglects the building's performance. Therefore, instead of defining one value which is the deformation capacity, it is possible to define more than one value according to the building performance level and this is the performance-based design method.

The performance-based design does not rely on only one aspect, which is the deformation capacity but takes into account the building performance level, and we are able to determine more than just the capacity point. Each point represents a specific performance level of the building (Shah \& Patel, 2011; Tyagi \& Tyagi, 2018).

\section{BUILDINGS SPECIFICATIONS}

All building models consist of a ground floor and other storeys with an elevation of $3.2 \mathrm{~m}$ for all storeys.

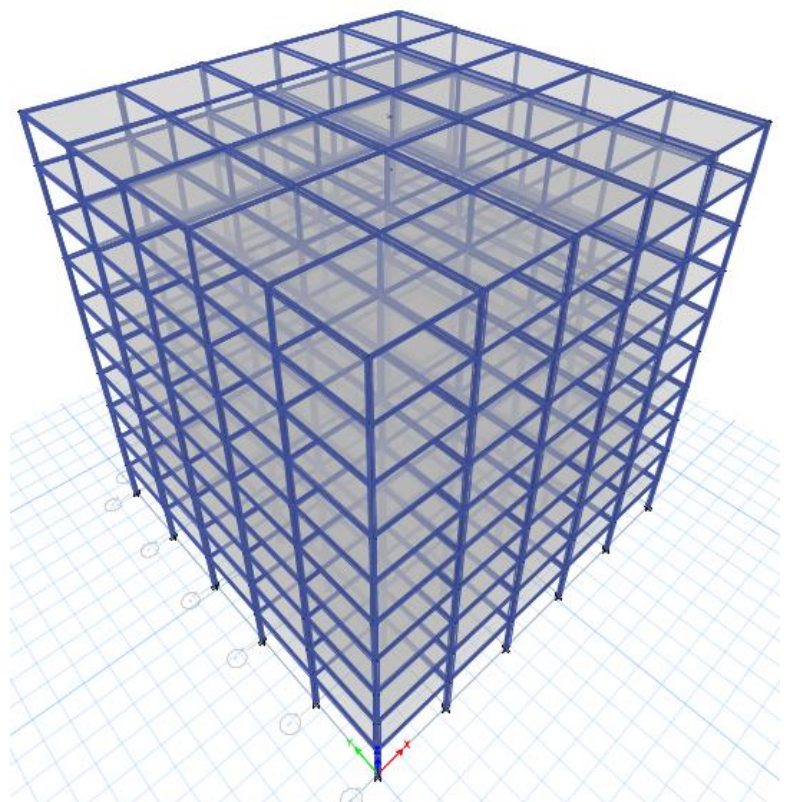

Fig. 1. 3D model of N10-L5
The steel modelled low-rise, mid-rise and high-rise buildings consisted of $\mathrm{G}+3$ (4-storey), G+6 (7-storey) and G+9 (10-storey) structures, with 3 different types of spans length, 5, 5.5, $6 \mathrm{~m}$. They have regular plans as shown in Fig. 1 The location was chosen at Lefkosa city in Northern Cyprus. All structures are modeled as frames and secondary beams under floor decks. Floor decks are modeled as a oneway membrane element, the diaphragm is defined as semirigid (Alkhattab et al., 2019).

\section{METHODOLOGY}

All models were designed in accordance with Euro code 3, using ETABS 2018 software, the smallest section has been chosen which can carry out the applied loads.

The loads applied as follow, dead load is calculated by the software, the live load is assumed $2 \mathrm{kN} / \mathrm{m}^{2}$, super dead load has taken $1.5 \mathrm{kN} / \mathrm{m}^{2}$, and wind speed is assumed $15 \mathrm{~m} / \mathrm{s}$ according to TS498, Earth quick load with $10 \%$ exceedance within 50 years (NCSC2015) (Alkhattab et al., 2019).

\subsection{Linear static analysis}

The first step we must analyse is to design all buildings to have the best sections for all members.

Linear static analysis was used to apply all load combinations according to Turkish standard TS 498-97 for wind load definition, TSC-2007 for earthquake parameters, and earthquake loads, both $\mathrm{X}$ and $\mathrm{Y}$ direction were used for positive and negative (Naughton et al., 2017).

Finally, all section was chosen as shown in Fig. 2.

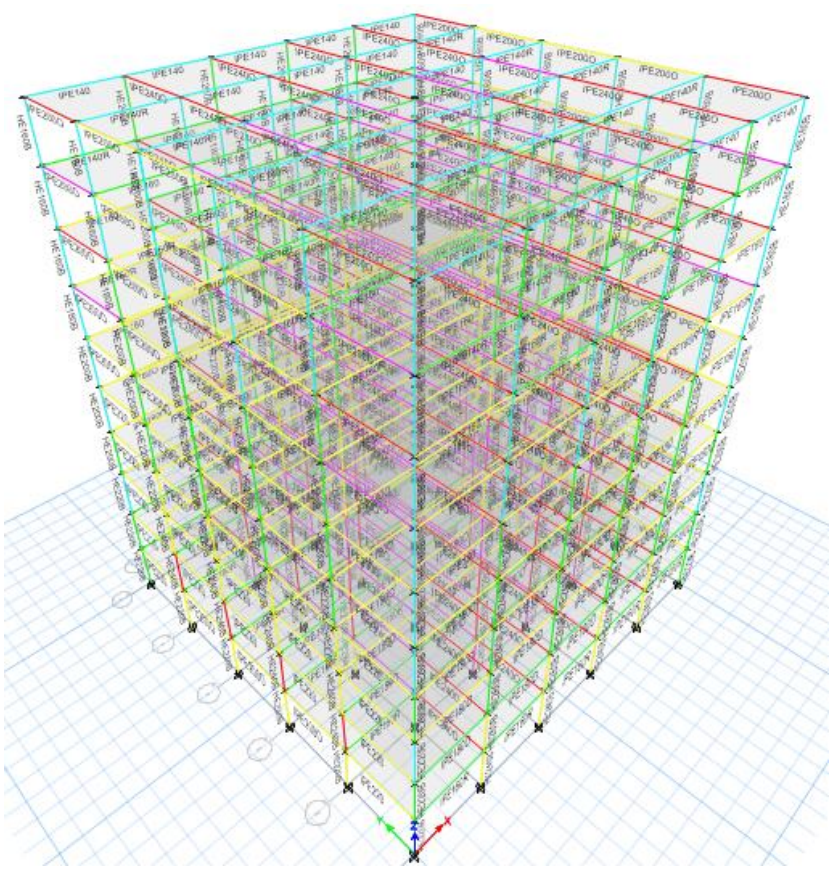

Fig. 2. Steel sections details N10-L5 


\subsection{Nonlinear static analysis}

It is a non-linear static approximation to the response shown by the origin when exposed to a dynamic seismic load. Based on its primitive form on the representation of the multi-degree of freedom MDOF response. In response to an equivalent sentence with a single degree of freedom ESDOF (AISC 2016, 2019).

This approximation includes the application of a side load distributed to the height of the model of origin subject to its vertical loads. This model takes into account the nonlinear properties of the elements, which are represented by the general non-linear behaviour curve (strength transmission) for each type of element that is resistant to side loads (Abhilash et al., 2009).

\subsection{Performance level}

An essential step before starting the procedures for nonlinear static analysis of any origin is to determine the level of performance required of it when it is exposed to certain seismic risk and to characterize the permissible damage in structural and non-structural elements at this level.

The level of performance is defined according to (ATC40) as the condition in which the studied origin is desired after being exposed to a specific ground movement. In other words, it is the maximum level of damage permitted in a building as a result of its exposure to a certain level of seismic risk. The codes classified the performance levels for any of the structures to a structural level SP and a nonstructural performance level NP (Monavari \& Massumi 2012).

Structural performance levels are known as:

- Immediate Occupancy (IO):

Limited structural damage is permitted with structural elements that resist vertical and horizontal loads maintaining their properties and capacity, allowing the facility to be used immediately after the earthquake.

- Life Safety (LS):

And in it, when an earthquake occurs, there will be damage to some of the structural elements and they are capable of repairing them, and damage will occur to the non-structural elements and it will not be suitable for repairing them.

- Collapse Prevention (CP):

Here, major damage occurs in the structural elements, but there will be no collapse of the building. Also, at this stage, injuries and deaths are expected to occur for individuals present in the building. At this point, the building cannot be repaired.

- Collapse:

The building collapses as well as some structural elements.

Thus, when designing the building, the designer should decide in determining the level of performance of the building he wants, meaning that he wants the building up to the IO, LS, or CP.

\subsection{Pushover Analysis (PA)}

The first step in any Pushover Analysis is to run a gravity analysis. Yielding will rarely occurs in the gravity analysis, however, the pattern of moment and forces that develop in the individual structural components will have an effect on the location and sequencing of hinges in the lateral load phase of the analysis. The gravity load analysis will also cause gravity-related P-Delta effects to be activated (if such effects are explicitly included in the analytical model (FEMA 451) (Honneshgowda \& Chandra 2017; Hoang et al., 2015).

\subsubsection{Pushover analysis procedure}

- Design all structure members using linear static analysis.

- Decide push displacement value considers a joint on the highest level of the building.

- Define loads, convert dead load to nonlinear static load.

- Define Push overload on X and Y direction.

- Assign hinge properties to the column and beam.

- Select all members then choose hinge to overwrite to have better results.

- Set loads to run, here just nonlinear load will set.

- Display pushover curve and calculate the stiffness as per the found values.

- Display Pushover Curve, base shear vs displacement, an example is shown in Fig. 3.

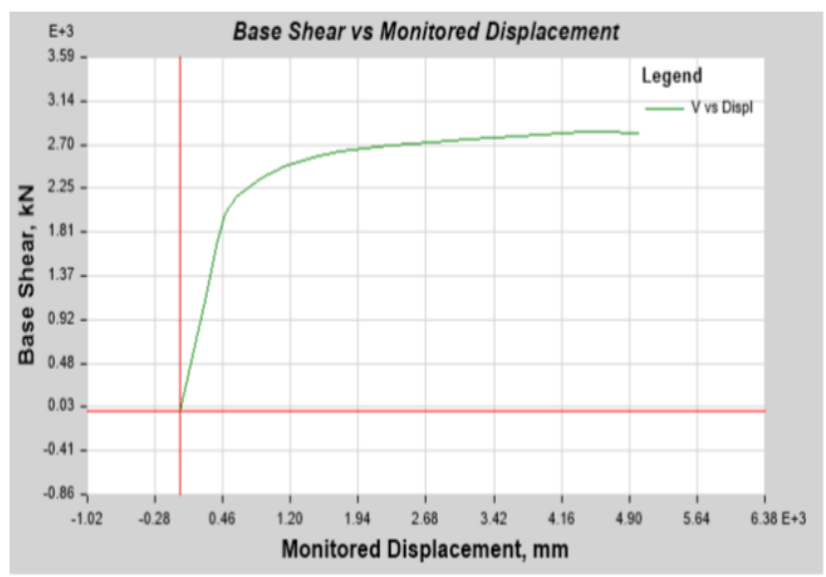

Fig. 3. Base shear (kN) vs monitored displacement (mm) of N10-L6

\subsection{Lateral loads used in nonlinear static analysis}

One of the most important factors influencing the sideload shape used in the non-linear static analysis in the result of the analysis due to its expression in the distribution 
of inertial forces arising in the elements of the studied building during its shock to the floor (Youcef et al., 2018).

The basic codes identified some side loads of linear and stationary shape during the stages of analysis that push the origin in one direction. They are used in the methods of analysis called Conventional Analysis Pushover (Maheri et al., 2003).

\subsection{Labelling system applied}

Since all frames have same steel properties, simple labelling has been used as ST-N-L-H- $f_{y}$.

where:

- ST: The structure type and ST refers to the steel structure

- N: Number of storeys

- L: span length

- H: Floor height

- $f_{y}$ : steel compressive strength

For short labelling used in figures N-L as the same $f_{y}$ (S275) and the same type of floor heights had been used.

\section{STRENGTH AND STIFFNESS}

Buildings along with other structures, and all parts thereof, shall be designed and constructed with adequate strength and stiffness to provide structural stability, protect nonstructural components and systems (ASCE).

Structural systems, and members thereof, should be designed under service loads to have enough stiffness to limit deflections, lateral drift, vibration, or any other deformations that adversely affect the intended use and performance of buildings and other structures based on the requirements outlined in the applicable codes and standards, or as specified in the project design criteria (Hashemi et al., 2018).

\subsection{The relation between plastic hinges and stiffness}

Fig. 4 shows the relation between base shear and stiffness.

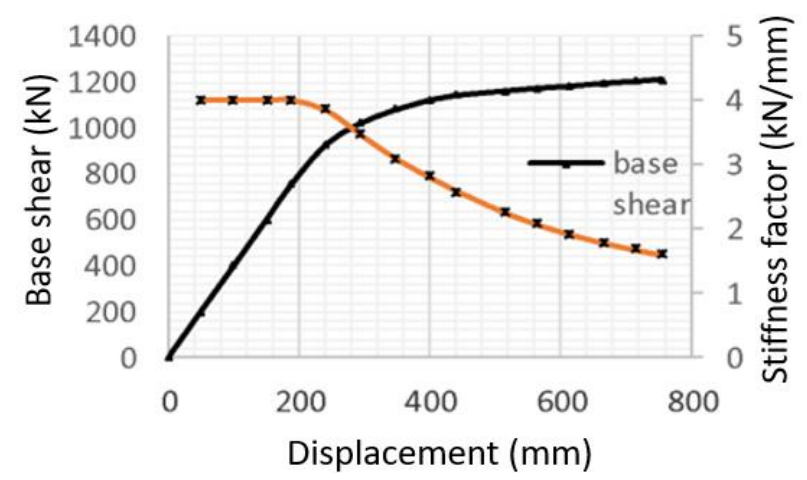

Fig. 4. Relation between base shear and stiffness
As the relation displacement-base shear is linear the stiffness does not change unless there are no hinges formed (Papanikolaou et al., 2008)

\section{RESULTS AND DISCUSSIONS}

The results are shown in Figs 5 to 10 .

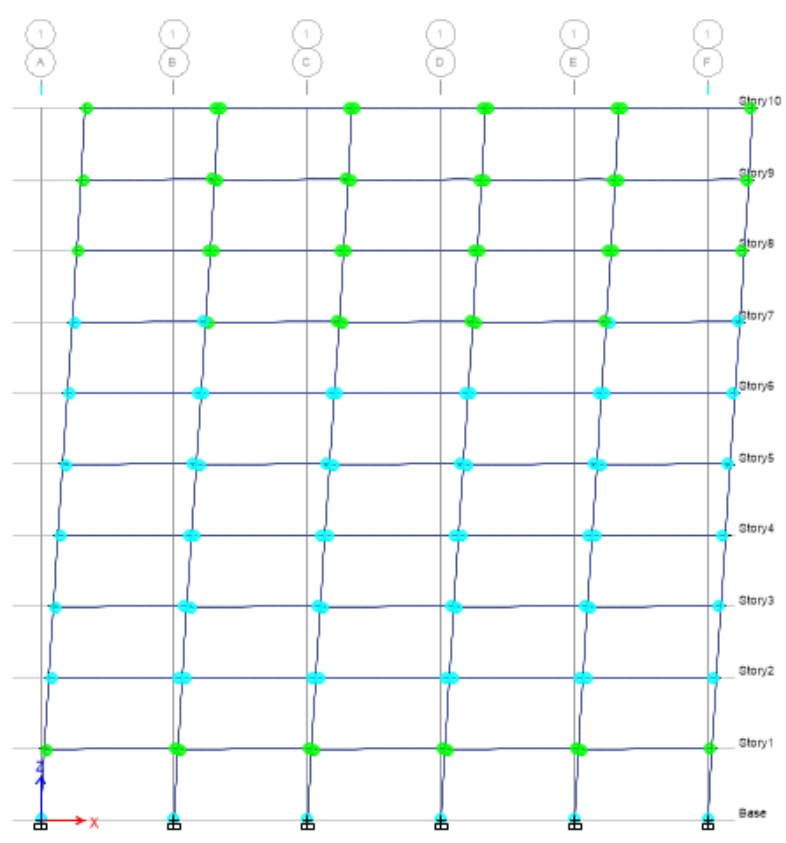

Fig. 5. Plastic hinges formation, ST-10-6-3.2-S275

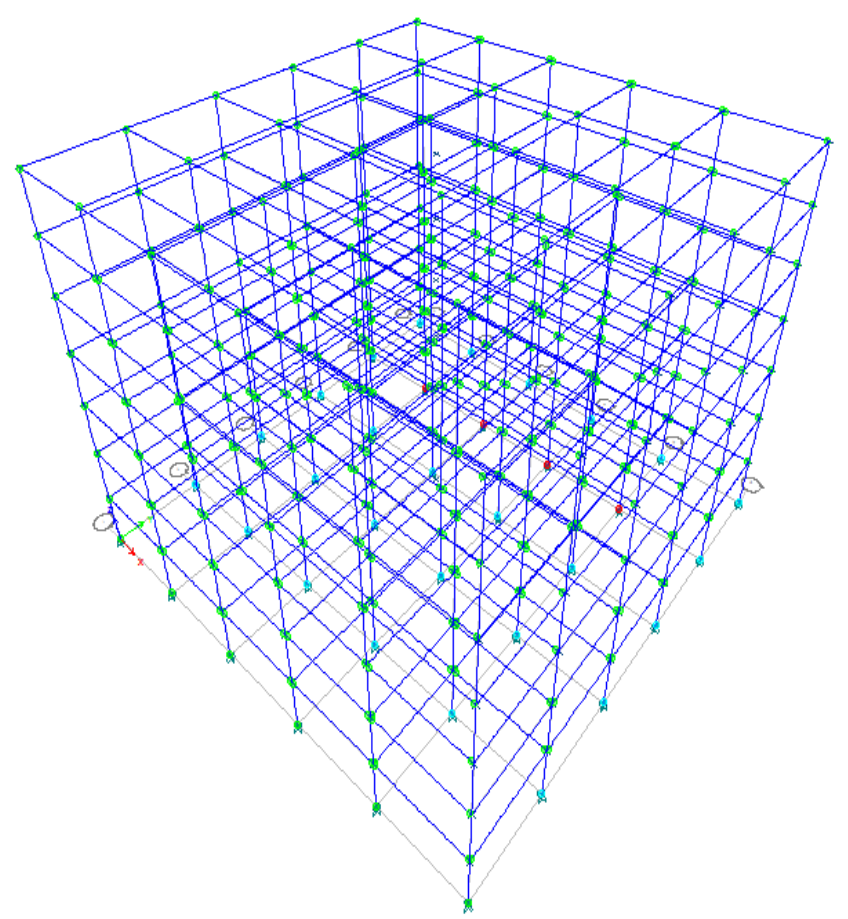

Fig. 6. Formation places of plastic hinges N7-L6 


\subsection{The effect of buildings height on stiffness factor (K)}

The stiffness increases by increasing the height of the building.

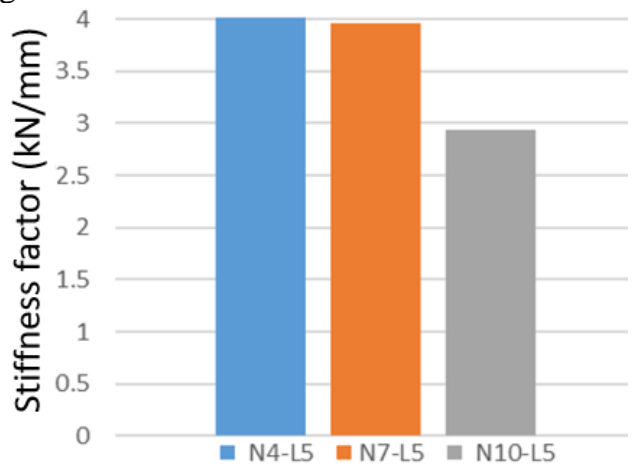

Fig. 7. Initial stiffness factor comparison of N4, N7, N10 buildings for same spans length

\subsection{The effect of span length on the stiffness factor}

The following figures show the effect of span length for the same height stiffness factor.

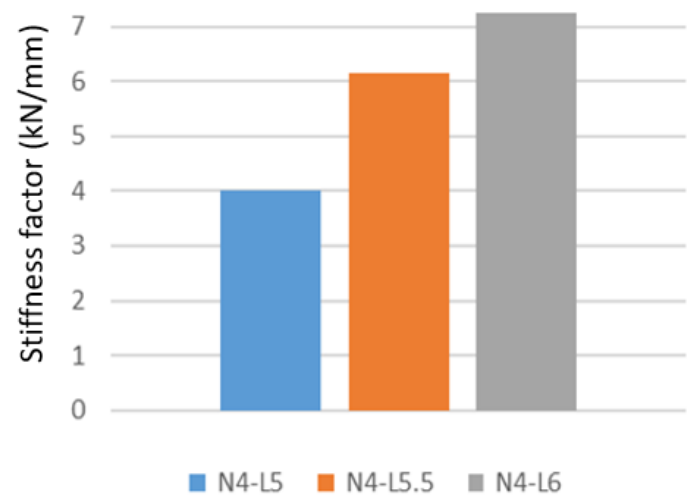

Fig. 8. Initial stiffness factor comparison of N4 buildings for different spans length

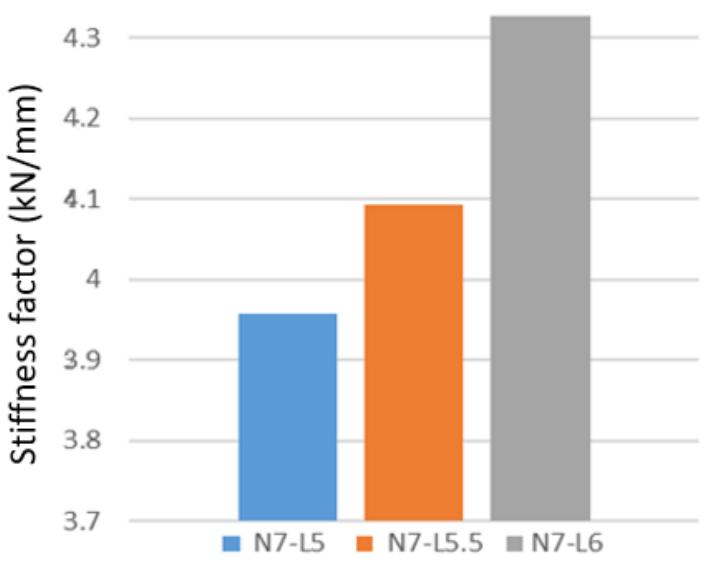

Fig. 9. Initial stiffness factor comparison of N7 buildings for different spans length

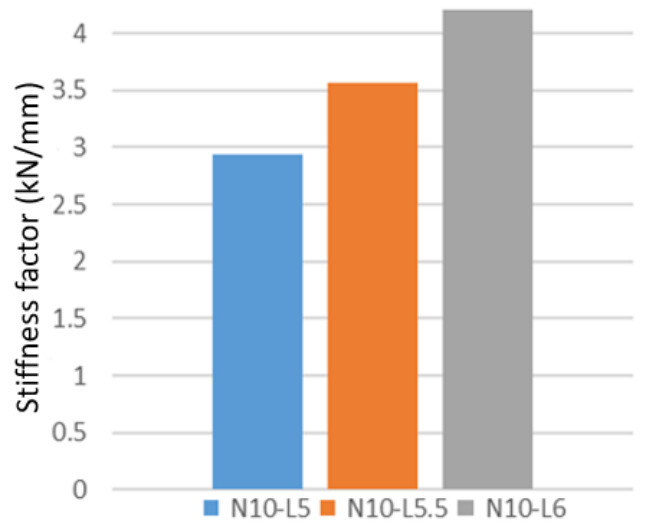

Fig. 10. Initial stiffness factor comparison of N10 buildings for different spans length

The results prove that stiffness increases with the increasing span length for the same height of buildings.

\section{CONCLUSION}

This paper provided a clear study on the plastic-hinge analysis for 3D frames with different span lengths and different floor heights. It then gave a clear procedure for non-linear analysis step by step, first, by applying linear analysis and then with results a study about the stiffness of different number of floors.

Three kinds of buildings have been studied, high-rise, mid-rise, and low-rise, buildings with three different span lengths.

The results have shown that the stiffness becomes less as the height of the building increases. This brings us to believe that low-rise buildings are stiffer than high-rise buildings and stiffness of the building declines as the span length decreases. In conclusion, 3D frames become stiffer if we increase the base area of the building.

\section{REFERENCE}

[1] Abhilash, R. et al. (2009). Effect of lateral load patterns in pushover analysis. 10th National conference on technological trends (NCTT09). At Trivandrum, India, Volume: College of Engineering Trivandrum, 1-5.

[2] ACI (2014). Building Code Requirements (ACI 318-14). ACI Committee, USA.

[3] AISC (2016). Specification for Structural Steel Buildings ANSI/AISC 360-16. American Institute of Steel Construction, USA.

[4] AISC (2019). Companion to the AISC steel construction manual. American Institute of Steel Construction, USA.

[5] Alkhattab, M. Resatoglu, R., Sadeghi, K., Alibrahim, B. (2019). Seismic Performance of Steel Frames with Inverted V-Braces for North Cyprus. International 
Journal of Innovative Technology and Exploring Engineering, 9(1), 4314-4320.

https://doi.org/10.35940/ijitee.a4956.119119

[6] Habibullah, A., \& Pyle, S. (1998). Practical Three Dimensional Nonlinear Static Pushover Analysis. Structure Magazine, 1-4.

[7] Hashemi, S. S., Sadeghi, K., Vaghefi, M., \& Siadat, S. A. (2018). Evaluation of Ductility of RC Structures Constructed with Bubble Deck System. International Journal of Civil Engineering, 16(5), 513-526. https://doi.org/10.1007/s40999-017-0158-y

[8] Hoang, V.-L., Nguyen Dang, H., Jaspart, J.-P., \& Demonceau, J.-F. (2015). An overview of the plastichinge analysis of 3D steel frames. Asia Pacific Journal on Computational Engineering, 2(1). https://doi.org/10.1186/s40540-015-0016-9

[9] Honneshgowda D. B., \& Chandra, B. S. S. (2017). Plastic Analysis of Steel Structure. International Journal for Scientific Research \& Development, 5(04), 498-501.

[10] Leelataviwat, S., Goel, S. C., \& Chao, S-H. (2015). Plastic versus elastic design of steel structures. In structural engineering and geomechanics. In Encyclopedia of Life Support Systems (EOLSS), Developed under the Auspices of the UNESCO, Eolss Publishers, Paris, France.

[11] Macedo, L., Silva, A., \& Castro, J. M. (2019). A more rational selection of the behaviour factor for seismic design according to Eurocode 8. Engineering Structures, 188, 69-86. https://doi.org/10.1016/j.engstruct.2019.03.007

[12] Maheri, M. R., Kousari, R., \& Razazan, M. (2003). Pushover tests on steel X-braced and knee-braced RC frames. Engineering Structures, 25(13), 1697-1705. https://doi.org/10.1016/s0141-0296(03)00150-0

[13] Monavari, B., \& Massumi, A. (2012). Estimating displacement demand in reinforced concrete frames using some failure criteria. International Journal of Advanced Structural Engineering, 4(1), 4. https://doi.org/10.1186/2008-6695-4-4

[14] Naughton, D. T., Tsavdaridis, K. D., Maraveas, C., \& Nicolaou, A. (2017). Pushover Analysis of Steel Seismic Resistant Frames with Reduced Web Section and Reduced Beam Section Connections. Frontiers in Built Environment, 3(59), 1-15. https://doi.org/10.3389/fbuil.2017.00059

[15] Papanikolaou, V. K., Elnashai, A. S., \& Pareja, J. F. (2006). Evaluation of conventional and adaptive pushover analysis II: Comparative results. Journal of earthquake engineering, 10(1), 127-151. https://doi.org/10.1080/13632460609350590

[16] Shah, M. D., \& Patel, S. B. (2011). Nonlinear static analysis of R.C.C. frames. National Conference on recent trends in Engineering and technology, 13-14 May 2011, India.
[17] Sullivan, T. J., Saborio-Romano, D., O’Reilly, G. J., Welch, D. P., \& Landi, L. (2018). Simplified Pushover Analysis of Moment Resisting Frame Structures. Journal of Earthquake Engineering, 1-28. https://doi.org/10.1080/13632469.2018.1528911

[18] Tyagi, B., \& Tyagi B. S. (2018). Seismic response study of multistoried reinforced concrete building with fluid viscous dampers. International Research Journal of Engineering and Technology (IRJET), 5(5), 22672271.

[19] Tzimas, A. S., Karavasilis, T. L., Bazeos, N., \& Beskos, D. E. (2017). Extension of the hybrid force/displacement (HFD) seismic design method to 3D steel moment-resisting frame buildings. Engineering Structures, 147, 486-504. https://doi.org/10.1016/j.engstruct.2017.06.013

[20] Youcef M., Abderrahmane K., \& Benazouz C. (2018). Seismic Performance of RC Building Using Spectrum Response and Pushover Analyses. In: Rodrigues H., Elnashai A., Calvi G. (eds) Facing the Challenges in Structural Engineering. GeoMEast 2017. Sustainable Civil Infrastructures. Springer, Cham. 